\title{
The Artistic Relationship Between Themed Wall Decoration and Interior Space
}

\author{
Wenjin Zhao ${ }^{1, *}$ \\ ${ }^{1}$ Guangzhou College of Technology and Business, Guangzhou, Guangdong 510850, China \\ *Corresponding author. Email: 22225734@qq.com
}

\begin{abstract}
People's higher demand for the practicality and applicability of space environment puts forward higher requirement for the artistic expression of interior space design. Themed wall decoration suitable for space decoration and interior design can have a unique expression of space. This paper sorts out the forms of themed wall decoration in interior space design, and on this basis carries out research on the interactive relationship between themed wall decoration and interior space environment. In addition, the expression and structure of themed wall decoration in interior space design are explored. Themed wall decoration is integrated with interior space design to discuss the artistic value and development trend of themed wall decoration in interior space design.
\end{abstract}

Keywords: Themed wall decoration, Interior space, Decorative arts.

\section{INTRODUCTION}

The improvement of material living standard and living quality prompt people to value the unity of art, function and aesthetics in addition to practicality when choosing dwellings. The interior wall decoration satisfies the combination of functionality and aesthetics. The development of science and technology and of modern craft has promoted the diversified development of wall decoration. The characteristics of modern and traditional wall decoration are combined, and a variety of artistic techniques are used to show the richness of modern life and achieve a high degree of unity of functionality and aesthetics. As interior decoration, wall decoration beautifies people's life in a specific space environment and becomes an important part of interior space decoration.

Themed wall decoration can exist independently, on the other hand, it depends on other things to exist. Themed wall decoration is an independent artistic work, which has unique artistic charm. Wall decoration brings people the enjoyment of the senses and the joy of the spirit. The ornamental effect created is the highly unified decoration and aesthetic of the wall decoration art. The wall decoration with perfect ornamental effect is the comprehensive performance of the material, form and color of the work itself, and plays a role alone in the space environment. The design of wall decoration must consider the space environment at the same time. The overall atmosphere of the indoor space environment should be consistent with the material, form, color and subject of the wall decoration, but also to consider the wall decoration, interior space function, and the psychological aesthetic needs of the viewer. The dual artistic characteristics of themed wall decoration are both contradictory and complementary, which are determined by its specific decorative function.

To a certain extent, wall decoration art is the comprehensive application of science and technology, modern technology and modern materials, which can give full play to the diverse functions of the material itself. The characteristics of modern and traditional wall decoration art can be combined, using a variety of artistic techniques to express the rich characteristics of modern life, to achieve a high degree of unity of functionality and aesthetics. As interior decoration, wall decoration beautifies people's life in a specific space environment and becomes an important part of interior space decoration. 


\section{THE INTERACTION OF THEMED WALL DECORATION AND INTERIOR SPACE INTERACTION}

The beauty of interior space comes from people's perception of sight, hearing and touch. The most essential function of themed wall decoration art is to establish a truly suitable environment and space for human habitation, so that people's sense of touch, vision and hearing can be satisfied. Among them, the visual perception is crucial to the cognition of interior space, and the discrimination of craft and materials largely depends on this organ, depending on the different texture of the material itself. The sense of touch can also be used to recognize wall decorations, allowing people to identify the nature and attributes of things through touch, such as material or type, etc.

The wall decoration art in the space presents a kind of aesthetic consciousness after materialization. Such consciousness has certain requirements for the creators' own emotions. The most important thing is to make the space enjoyable for people physically and mentally. The purpose that people undertakes creation to interior space is to grasp his psychology, which requires the creation of corresponding method and means. Therefore, on the basis of satisfying people's needs, one's own aesthetics should be well grasped. The interior with wall decoration should reflect the individual value, foil and render the spatial effect, and express the specific art bridge through the space and form communication.

\subsection{Design of Space Environment and Themed Wall Decoration}

The wall and decoration are inseparable and interdependent. From the design of space environment, wall decoration creation should conform to its rules and requirements, according to the function and characteristics of space environment itself for artistic creation. The theme spirit and inner aesthetics embodied in the wall decoration should be in line with the development of the whole era, and the aesthetic taste should be in line with the aesthetic views of the public. The environment in different periods has a great influence on the theme and aesthetic creation of the themed wall decoration. Different regions and environments provide the theme with local characteristics for the creation of the themed wall decoration, while the specific environment has an influence on the material, composition and color. Therefore, the artistic creation of themed wall decoration should adapt to its requirements and harmonize with the specific characteristics and functions of the overall space environment. The theme and aesthetic of themed wall decoration must be consistent with the times, and the public's aesthetic interest.

\subsection{The Artistic Appeal of Themed Wall Decoration to Space Environment}

Wall decoration is the ornament and separation of the whole space environment, so as to present the artistic charm of the whole space to a large extent, and create an experience atmosphere. Although the new spatial structure will change the way the space is used, the whole space should be composed of systems and structures. In terms of function, the themed wall decoration does not significantly change the role of the space wall and the use of space, it will have different aesthetic effects in different Spaces and environments in the aesthetic, and then promote people to conduct emotional communication. Different people have different feelings about the space. Psychologically and visually, the exterior and contents of the whole space often have different atmospheres and different artistic appeal.

"The Glory of San Ignazio" by Andrea Pozzo resolves the gap between the roof and the walls. "The Glory of San Ignazio" (also Saint Ignatius ascended to heaven), the giant ceiling painting of the church of San Ignazio, is another example. Andre Pozzo made the dome an extension of the building. On the dome, he drew endless high walls leading straight to the sky. With the help of the limited space, he expressed an infinite space, which broke through the original limited scope and gave full play to the Baroque perspective painting. Whether in art or in content, the artistic effect presented is consistent with the style of the church, which will leave a deep impression on the art appreciation. The designer of the space is a magician, giving the viewer a relatively bright and perfect effect and impression. Thus it can be seen that the elements of the themed wall decoration can be closely combined with the Bark-style space with a sense of movement and penetration to achieve the effect of arousing the viewer.

The length, width and height of the whole space are closely related to the structural nature of the whole space, and the whole space tends to have a greater impact on the viewer's spirit and aesthetic feelings in terms of scale, which will then restrict the themed wall decoration. There should be enough visual distance between the viewer and the themed wall decoration, so that the effect can be complete. 


\section{DESIGN IDEAS OF THEMED WALL DECORATION AND INTERIOR SPACE}

The artistic conception and style of the themed wall decoration and the interior space wall should be coordinated with each other. The environment and form of the space complement each other. It will form a good match visually, and expand the scope of the environment of the whole space with contradiction and environment. Themed wall decoration is included in the spatial design of the spatial environment, all will be presented in the spatial aspect, just as all will be presented in human activities such as practice, thought. The design of themed wall decoration is often not limited to the plane characteristics of two-dimensional space, it enriches the wall space, so that the whole space is colorful, and then highlights the tension and vitality.

\subsection{The Space Design Form of Themed Wall Decoration}

Themed wall decoration is confined to a specific spatial form in the space environment, and has a specific subordinate object. The composition of the space environment can often reflect the requirements of the space structure and design, the space style and appearance. The so-called spatial form is mainly generated by people or the whole society for a variety of needs of the whole space. Therefore, in the classification process of space, there appear industrial space, public space and civil space. Such as library, museum, concert hall, cinema, lecture hall and so on. Therefore, as an important part of the whole space, the artistic language and space of the themed wall decoration can show the unique social civilization and cultural characteristics of the nation. Themed wall decoration in the physical form should meet the requirements of spatial form, to build a good space environment. Before the design, its content and form should be considered, so that it cannot only obey the use of the space function, but also give full play to the role of its own and expression. In this way, the form of the space can be changed, the realization of artistic treatment of the space is achieved, and then have a good effect on the environment for beautification and decoration.

\subsection{The Space Design Structure of Themed Wall Decoration}

The independent themed wall decoration is bound to be constrained by the structure of the whole space. The so-called spatial structure mainly refers to the specific image and structure presented by the space. For the wall decoration, the quality of its works often depends on the artistic effect of the work itself. On the contrary, the role it plays in the structure of the whole space should be considered and studied. Therefore, the position of the themed wall decoration will be subject to the division of the whole space to some extent, and will also be subject to the constraints of various structures such as the door beam. These walls are restricted by the spatial structure, resulting in the design of themed wall decoration must conform to a variety of specific structural forms, consistent with the surface of the spatial entity, and maintain an internal connection with the structural logic of the space. Themed wall decoration is mostly conceived and made for a specific location in a space. Wall elements should be taken into account, so that it does not affect the overall effect of the wall, but also reflect the characteristics of the spatial structure, so that the wall decoration and the space environment set off each other.

\subsection{Space Environment Art of Themed Wall Decoration}

As an element of space art, the themed wall decoration should use a unified and harmonious language, obey the style and function of the whole space in form and content, and consider the different needs of the space. Therefore, the creation will be subject to a lot of constraints at the very beginning, which requires the artist to analyze the function, shape and environment of the space in advance, as well as the angle, viewing distance, lighting, space texture, material texture and the mentality of the occupants.

Themed wall decoration, as a kind of space surface, is often limited by space. An excellent artist should put his feelings into a more complex and broad environment, and then create a better cultural environment. The continuous development of behavioral science, the innovation and exploration of new design methods and aesthetic theories urge the creators to follow the systematic thought in methodology and reflect and explore the urban planning from the whole. On the contrary, the development of space technology has enabled the development of aesthetic inquiry, which has become a goal to pursue. 


\section{CONCLUSION}

The function of themed wall decoration is constantly evolving, and its application in the space environment can be traced back thousands of years. With the passage of time, its form of expression is more and more diverse, and the continuous development of technology is bound to give birth to more multi-functional themed wall decoration with rich connotation. Themed wall decoration cannot really change the space environment to a large extent, but it can make up for the defects of the space on the basis of meeting the needs of the space and eliminate the boredom of the wall. It is an integral part of the space environment and forms a unified decorative character with the environment. In addition, to a large extent, it can extend the visual sensation in a limited range. This approach adheres to a people-centered approach that provides spiritual and aesthetic resonance for the masses. In the era of rapid development of information, people's life and the theme of the wall ornaments are closely related. Therefore, the inheritance of themed wall decoration should also conform to the development of the times and the needs of science and technology. This also highlights that modern themed wall decoration makes up for traditional themed wall decoration with single function.

\section{AUTHORS' CONTRIBUTIONS}

This paper is independently completed by Wenjin Zhao.

\section{REFERENCES}

[1] [U.S.] Rudolf Arnheim. Art and Visual Perception: A Psychology of the Creative Eye. Translated by Teng Shouyao. Sichuan: Sichuan People's Publishing House, 2019(03): 187. (in Chinese)

[2] Xi Kailai. Architecture and mural space. China Building Materials Science \& Technology, 2013 (01). (in Chinese)

[3] Wang Lu; Statement. On the Aesthetic Display and Application Research of Mural Art in Interior Design. Journal of Chongqing University of Science and Technology (Social Sciences Edition), 2020(07). (in Chinese)

[4] Li Xuesheng. The aesthetics and application of ceramic murals in indoor environment design. Appreciation, 2019(22). (in Chinese)
[5] Zhou Yang. Research on the application of ceramic murals in architectural interior design. Appreciation, 2019(12). (in Chinese)

[6] Liu Chang, Xin Hongkai. Research on the application of grotto fresco colors in modern interior design under the concept of symbiosis between the new and the old. Fine Arts Literature, 2019(05). (in Chinese) 